\title{
Mustard's operation for patients with ventriculoarterial concordance Report of two cases and a cautionary tale
}

\author{
P ARCIPRETE, F J MACARTNEY, M DE LEVAL, J STARK \\ From the Thoracic Unit, The Hospital for Sick Children, London
}

SUMMARY Three patients with ventriculoarterial concordance and an abnormal atrioventricular connexion were investigated. One patient had total anomalous pulmonary venous connexion to a left vertical vein. In 1972 this was repaired and a ventricular septal defect was closed, but the presence of atrioventricular discordance was missed and the patient died. In the other two patients, Mustard's operation resulted in survival. One patient had situs solitus and atrioventricular discordance with an associated ventricular septal defect, which was closed. The other had left isomerism (quasi solitus) with an ambiguous atrioventricular connexion (quasi discordant). A previously noted ventricular septal defect had spontaneously closed.

Intra-atrial baffle procedures (venous switches) such as Mustard or Senning operations are normally used to compensate congenitally determined single switches in the circulation. By far the commonest of these is complete transposition, in which the patient has a single switch (ventriculoarterial discordance with atrioventricular concordance). A much rarer indication for venous switching occurs when the single switch is at atrioventricular level and there is no switch at ventriculoarterial level-that is, there is ventriculoarterial concordance. In fact, only eight such operations have been hitherto described. ${ }^{1-6}$ The purpose of this report is to document two further examples and to illustrate the danger of an incorrect preoperative diagnosis in a third.

\section{Patients and methods}

CASE 1

A $3 \frac{1}{2}$ year old girl was referred from Germany with a diagnosis of total anomalous pulmonary venous connexion. The angiocardiograms on which this diagnosis was based were not of high quality, but on reviewing them it was clear that there was situs solitus with atrioventricular discordance and ventriculoarter-

Requests for reprints to Mr J Stark FRCS, Thoracic Unit, The Hospital for Sick Children, Great Ormond Street, London WCIN 3JH.

Accepted for publication 14 November 1984 ial concordance, a ventricular septal defect, and total anomalous pulmonary venous connexion to a left vertical vein. The ventricles were normally related for atrioventricular discordance, but the great arteries were side by side with the aorta to the right.

On physical examination, she had moderate cyanosis and finger clubbing. There was clinical hypertrophy of both ventricles and a systolic thrill at the lower left sternal border. On auscultation, the first heart sound was normal, the second heart sound was split, and there was a pansystolic murmur at the lower left sternal border. There was no diastolic murmur and no sign of heart failure. Her chest $x$ ray film showed a large heart with increased pulmonary vascular markings and a wide mediastinum, and her electrocardiogram showed sinus rhythm and right atrial hypertrophy with a PR interval of $0.16 \mathrm{~s}$, a QRS interval of $0.10 \mathrm{~s}$, and a somewhat atypical right bundle branch block pattern.

\section{Diagnosis}

She underwent repeat cardiac catheterisation in June 1972. The vertical common pulmonary vein was entered and contained blood with an oxygen saturation of $92 \%$. There was a $10 \mathrm{~mm} \mathrm{Hg}$ mean pressure gradient between the vertical vein and the superior vena cava. Both ventricular systolic pressures were equal at $90 \mathrm{~mm} \mathrm{Hg}$ and the pulmonary artery pressure was $75 / 40 \mathrm{~mm} \mathrm{Hg}$. The pulmonary and systemic artery oxygen saturations were equal $(80 \%)$. Repeat cineangiograms were performed with injection into 
the common pulmonary vein, pulmonary trunk, and left sided ventricle, but a fault in processing destroyed the frontal plane film. She was therefore referred for surgery with a diagnosis of situs solitus with normal cardiac connexions, total anomalous pulmonary venous connexion to a vertical vein, and a ventricular septal defect.

\section{Operation}

At operation a ventricular septal defect $2 \mathrm{~cm}$ in diameter was closed through the right atrioventricular valve. An anastomosis was constructed between the pulmonary venous confluence and the left atrium, and a patent foramen ovale was closed. The common pulmonary vein was ligated. She could not be weaned from cardiopulmonary bypass despite an attempt to reopen the ventricular septal defect, and she died on the operating table.

\section{Necropsy findings}

At necropsy, the reason for the operative death became clear. The bronchi and atria were in situs solitus. Pulmonary venous return had been successfully directed to the left atrium and a patent foramen ovale closed, but these two procedures had been disastrous in the presence of atrioventricular discordance with ventriculoarterial concordance. The right sided mitral valve had two sets of papillary muscles and no insertion into the septum.

There was a large perimembranous ventricular septal defect excavating both inlet and outlet septa, such that posteriorly it was roofed by the two atrioventricular valves in continuity, and anteriorly it. was roofed by the outlet septum. Into the underside of this was inserted the anteroseptal commissure of the tricuspid valve (the remainder of which was normal). There was mild malalignment of the trabecular and outlet septa such that the aortic valve overrode the septum slightly, originating $85 \%$ above the left ventricle.

There was a bilateral infundibulum, with $7 \mathrm{~mm}$ of muscle separating the mitral and aortic valves and 5 $\mathrm{mm}$ of muscle separating the tricuspid and pulmonary valves. The great arteries lay side by side with the aorta to the right - that is, with a slight clockwise spiral as they ascended. The right ventricle was a little small, being only two thirds the length of the left ventricle, and lay to its left, the septal orientation being as is usually found in congenitally corrected transposition. The coronary artery pattern was inverted.

\section{CASE 2}

A 4 month old baby boy, weighing $5.2 \mathrm{~kg}$, was admitted to our unit in congestive heart failure. Poor feeding and moderate cyanosis at rest had been noted since birth. On examination the child was dyspnoeic and severely cyanosed on crying. His pulse rate was 145 beats/minute and his blood pressure $100 / 60 \mathrm{~mm}$ Hg. On auscultation no cardiac murmurs were detected. His chest was clear. There was no hepatomegaly, and all peripheral pulses were palpable. Laboratory investigations showed a haemoglobin concentration of $17.7 \mathrm{~g} / \mathrm{dl}$ and a packed cell volume of $51 \%$. His chest radiography showed pulmonary plethora with mild cardiomegaly, and his electrocardiogram recorded sinus rhythm, right axis deviation, and a deep $Q$ wave in leads II, III, aVF and V4R. There was a dominant $R$ wave in V4R with an upright $T$ wave.

\section{Diagnosis}

Cardiac catheterisation and angiocardiography showed situs solitus, atrioventricular discordance, ventriculoarterial concordance, ventricular septal defect, and patent foramen ovale. The great arteries were normally related, spiralling clockwise as they ascended. There was a very short muscular subaortic infundibulum and a longer subpulmonary infundibulum. The intracardiac pressures were: mean right atrium $3 \mathrm{~mm} \mathrm{Hg}$, mean left atrium $14 \mathrm{~mm} \mathrm{Hg}$, right ventricle $70 / 0 \mathrm{~mm} \mathrm{Hg}$, left ventricle $70 / 0 \mathrm{~mm} \mathrm{Hg}$, pulmonary artery $70 / 30$ (mean 42 ) $\mathrm{mm} \mathrm{Hg}$, and systemic artery $70 / 50$ (mean 60$) \mathrm{mm} \mathrm{Hg}$. The aortic oxygen saturation was $54 \%$ and improved to $66 \%$ after balloon septostomy. The pulmonary artery oxygen saturation before septostomy was $92 \%$. In view of the severe degree of arterial desaturation and failure to thrive, it was decided to proceed to surgical correction.

\section{Operation}

After the pericardium had been opened the anatomy of the heart was assessed. The heart was enlarged. The pulmonary artery was anterior and to the left of the aorta, which was posterior and to the right. Both venae cavae were normally connected with the right atrium, which was on the right. The right atrium was connected to the morphologically left ventricle. The pulmonary veins emptied into the left atrium, which drained to the somewhat superior and leftward morphologically right ventricle. There was only one large coronary artery arising from the aorta anteriorly, giving off the left and the right coronary arteries which were distributed on the anterior aspect of the heart. After cannulation of the aorta and both venae cavae, cardiopulmonary bypass was established. The patient was cooled to $20^{\circ} \mathrm{C}$ nasopharyngeal temperature, the aorta was cross clamped, and cardioplegic solution was infused. The right atrium was opened and it was possible to confirm the angiographic diagnosis. The ventricular septal defect was located in the inlet septum and was closed through a short right ven- 


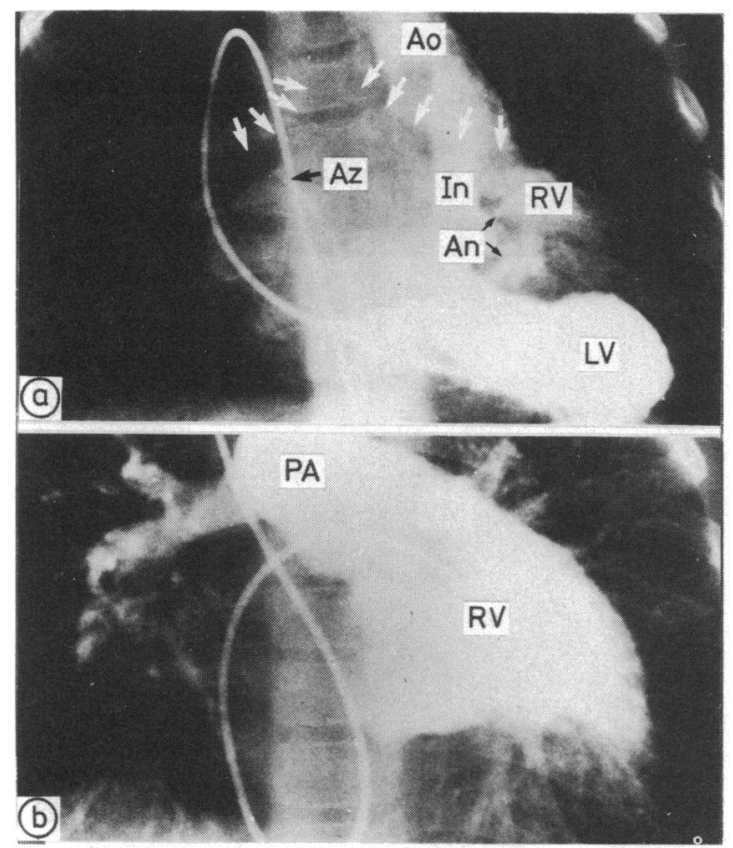

Fig. 1 Case 3: left ventricular angiocardiograms (frontal plane). (a) Shows the catheter passing round an azygos continuation $(A z)$ into the right sided atrium and thence to the left ventricle $(L V)$, from which the aorta $(A o)$ opacifies via a subaortic infundibulum (In). An aneurysm (An) of the membranous septum is seen, through which two tiny ventricular septal defects (small black arrows) opacify the right ventricle. Note the two long morphologically left bronchi (white arrows). (b) Shows the catheter, having crossed a patent foramen ovale, entering the right ventricle $(R V)$, from which the pulmonary trunk (PA) opacifies.

triculotomy using a Dacron patch. Anteriorly the stitches were inserted on the morphological right side of the ventricular septum, according to the technique previously described to reduce the risk of injuring the His bundle. ${ }^{7}$ Mustard's operation was then performed using a pericardial patch. The new pulmonary venous atrium was enlarged with a woven Dacron patch. When perfusion was terminated the patient was in sinus rhythm. Postoperative systolic pressures were: aorta $100 \mathrm{~mm} \mathrm{Hg}$ and pulmonary artery $30 \mathrm{~mm} \mathrm{Hg}$. The postoperative course was uneventful, and the patient was discharged two weeks later in an excellent condition.

\section{Follow up}

After almost six years the patient was still asymptomatic and in sinus rhythm. Recatheterisation in January 1984 showed normal intracardiac pressures with no residual shunts and no evidence of caval pathway obstruction. A cross sectional echocardiogram showed typical atrioventricular discordance, with reversed offsetting of the atrioventricular valves. Precordial short axis views showed the typical "circle and sausage" appearance of normally related great arteries, the aorta being the circle and the right ventricular outflow tract and pulmonary trunk being the sausage.

CASE 3

A male child had had cyanosis and dyspnoea since the age of 2 weeks. Cyanosis and clubbing increased progressively, while exercise tolerance gradually decreased. At the age of 12 years he was investigated abroad. The diagnosis of transposition of the great arteries with a small ventricular septal defect and interruption of the inferior vena cava with right azygos continuation was made. Pressures at the time of cardiac catheterisation were equal in the two atria (mean $7 \mathrm{~mm} \mathrm{Hg}$ ). The pressure in the subpulmonary ventricle was $24 / 0-5 \mathrm{~mm} \mathrm{Hg}$ and in the pulmonary artery $22 / 7 \mathrm{~mm} \mathrm{Hg}$. The systolic pressure in the subaortic ventricle and aorta was $110 \mathrm{~mm} \mathrm{Hg}$. The pulmonary artery oxygen saturation was $86 \%$, whereas that in the frontal artery was $\mathbf{7 2} \%$.

The patient was lost to follow up. At 16 years of age he was referred to us for further evaluation and treatment. On examination, he was physically underdeveloped, with severe cyanosis and clubbing and was dyspnoeic at rest. His blood pressure was $120 / 60 \mathrm{~mm}$ $\mathrm{Hg}$. There was an ejection systolic murmur at the left sternal border and a split second heart sound. His chest was clear on auscultation. His liver was enlarged to $4 \mathrm{~cm}$ below the costal margin. The spleen was not palpable. All peripheral pulses were palpable and equal. Laboratory investigations showed a haemoglobin concentration of $22.8 \mathrm{~g} / \mathrm{dl}$ and packed cell volume of $72 \%$. Coagulation tests and serum electrolyte and blood urea concentrations were all within normal limits. His chest radiograph showed mild cardiomegaly with a cardiothoracic ratio of 0.54 and increased pulmonary vascular markings. His electrocardiogram recorded a superior $P$ wave axis with right axis deviation and right bundle branch block.

\section{Diagnosis}

A review of the angiocardiograms (Fig. 1) established a diagnosis of left atrial isomerism (quasi solitus), ambiguous (quasi discordant) atrioventricular connexion, ventriculoarterial concordance, left hand pattern of ventricular morphology, small ventricular septal defect in the aneurysm of the ventricular septum, aberrant right subclavian artery, atrial septal defect at the fossa ovalis, and interruption of the inferior vena cava with azygos continuation to the right superior vena cava. The pulmonary valve lay anterior to the right of the aorta, and the great arteries spiralled counterclockwise as they ascended. 

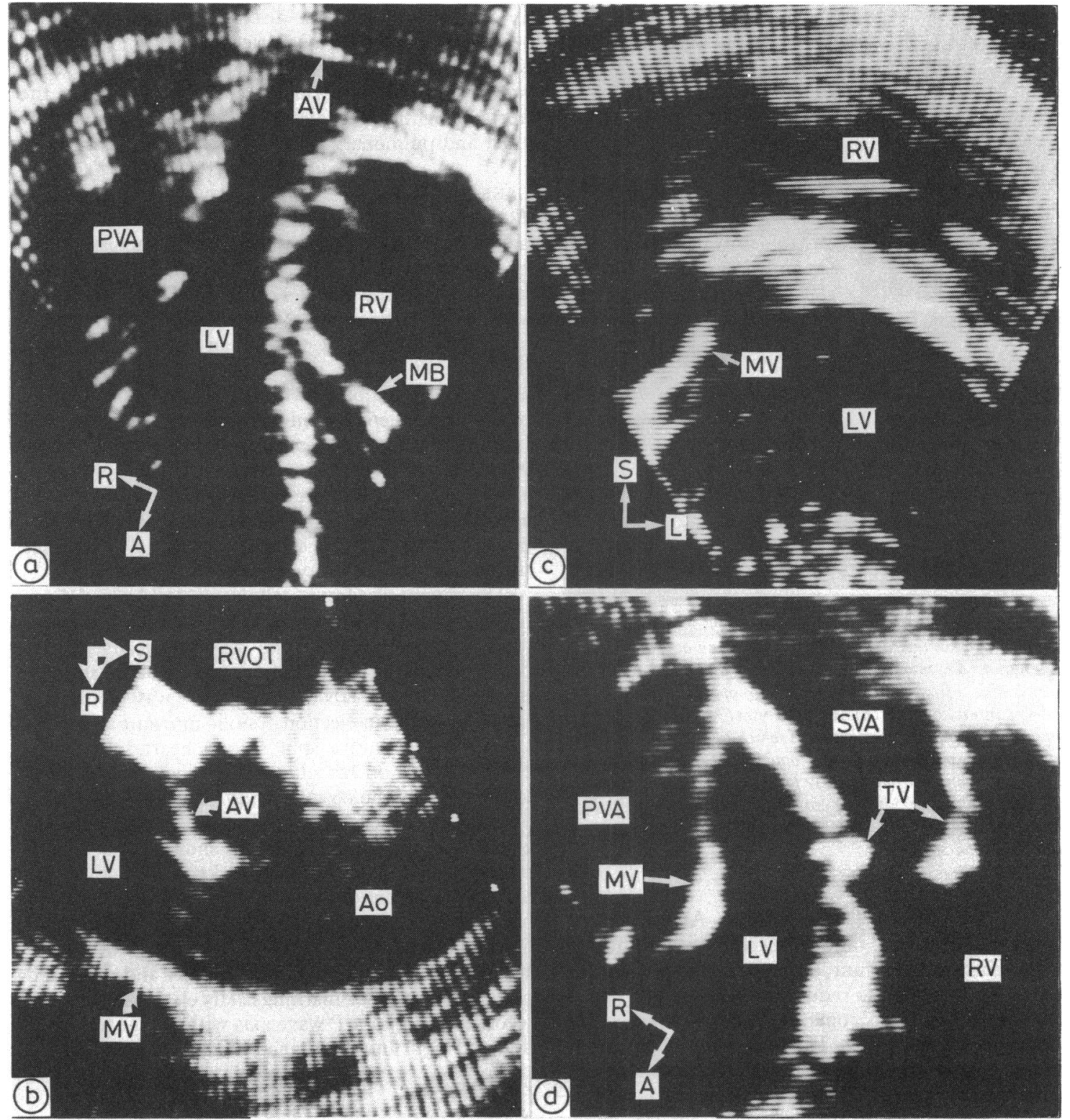

Fig. 2 Case 3 (after repair): cross sectional echocardiograms. (a) The apical four chamber cut, angled forward to show left ventricular outflow tract, shows the right ventricle $(R V)$ identified as such by the moderator band $(M B)$. The pulmonary venous atrium $(P V A)$ is now connected to the left ventricle $(L V)$, which has a normal outflow tract roofed by the aortic valve $(A V)$. (b) The parasternal long axis cut looks remarkably normal. Note the mitral valve (MV) and right ventricular oufflow tract (RVOT). Other abbreviations as above. (c) The subcostal paracoronal cut shows the right ventricle $(R V)$ above the left ventricle $(L V)$. The mitral valve $(M V)$ separates the $L V$ from what used to be the right sided morphologically left atrium. (d) The apical four chamber cut shows pronounced reversed offsetting of the mitral (MV) and tricuspid (TV) valves. Other abbreviations as above. A, anterior; $L$, lefi; $R$, right; $S$ superior.

\section{Operation}

At operation a midline sternotomy was performed and the pericardium resected for a patch. The outside anatomy of the heart was as expected from angiocardiography. Both atria were of left morphology. The heart was moderately enlarged. The pulmonary artery 


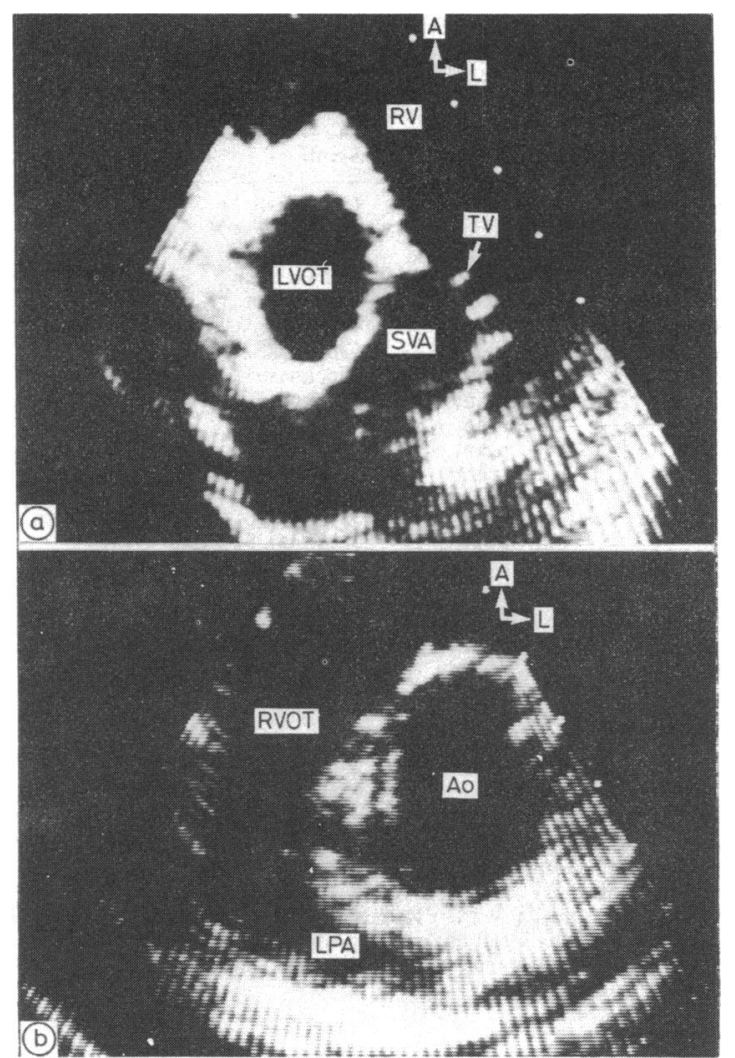

Fig. 3 Case 3: cross sectional echocardiograms in the parasternal short axis cuts showing (a) the systemic venous atrium (SVA), formerly the left sided left atrium, draining via the tricuspid valve $(T V)$ to the right ventricle $(R V)$, which winds around the left ventricular outflow tract (LVOT); and (b) at a slightly higher level, the right ventricular outflow tract (RVOT) leading out to the pulmonary trunk and left pulmonary artery (LPA), which partly encircle the aorta (Ao). Note that these short axis views are orientated more or less as the mirror image of normal, indicating counterclockwise spiralling great arteries. $A$, anterior; $L$, left.

ascended to the right of the aorta, having arisen from the left sided morphologically right ventricle. The aorta was posterior and to the left, arising from the inferior and right sided morphologically left ventricle. The superior vena cava and hepatic veins entered the right sided morphologically left atrium, which was connected to the morphologically left ventricle, while the left sided morphologically left atrium received the pulmonary veins and emptied into the morphologically right ventricle.

In view of the rather small volume of the right sided left atrium, it was decided to perform the Mustard rather than the currently favoured Senning operation. After cannulation of the aorta, superior vena cava, and common hepatic vein, cardiopulmonary bypass was started and the patient cooled to $20^{\circ} \mathrm{C}$ nasopharyngeal temperature. The aorta was cross clamped and cardioplegia solution was infused to the root of the aorta. The right sided atrium was opened and the anatomy visualised. The right sided atrium opened into the morphological left ventricle through a valve which had all the characteristics of a mitral valve. The remnant of the atrial septum was resected and then the left atrioventricular valve visualised. It was a tricuspid valve. A ventricular septal defect was not found after careful inspection of the ventricular septum. It was therefore assumed that it had closed in the four years between cardiac catheterisation and operation. Mustard's operation with the modifications as usually practised in our unit ${ }^{8}$ was then performed. When completed, the cross clamp was removed, air evacuated from the heart, the patient rewarmed, and perfusion discontinued. At the end of the operation, the patient was in sinus rhythm with the following pressures: right ventricular systolic $40 \mathrm{~mm} \mathrm{Hg}$, pulmonary artery systolic $35 \mathrm{~mm} \mathrm{Hg}$, left ventricular systolic $80 \mathrm{~mm} \mathrm{Hg}$, aortic systolic $80 \mathrm{~mm} \mathrm{Hg}$, superior vena caval mean $12 \mathrm{~mm} \mathrm{Hg}$, and pulmonary venous atrial mean $10 \mathrm{~mm} \mathrm{Hg}$.

His postoperative progress was entirely uneventful and he was discharged two weeks postoperatively to return home. Before discharge, a cross sectional echocardiogram showed typical features of ventricular inversion, except that there was ventriculoarterial concordance. Parasternal short axis cuts appeared as a mirror image of the normal appearance, because of the counterclockwise spiralling of the great arteries (Figs. 2 and 3).

\section{Discussion}

These patients illustrate clearly the two ways in which the pulmonary and systemic circulations can be switched at atrioventricular level. The first two patients had atrioventricular discordance in that the right atrium was connected to the left ventricle and the left atrium to the right ventricle. The third, who had two atria, both of which were morphologically left, can only be described as having an ambiguous atrioventricular connexion. In planning surgical repair, however, it was helpful to note that the pulmonary veins drained to the left sided atrium and the systemic veins to the right sided atrium and to treat the patient as if he had situs solitus with atrioventricular discordance. Strictly speaking, therefore, the segmental anatomy would be described as left isomerism (quasi solitus) with an ambiguous atrioventricular connexion (quasi discordant) and ventriculoarterial concordance. ${ }^{y}$

Both conditions described here are extremely rare, 
Table Details of patients in the present study and in previous reports with ventriculoarterial concordance and atrioventricular discordance or quasi concordance

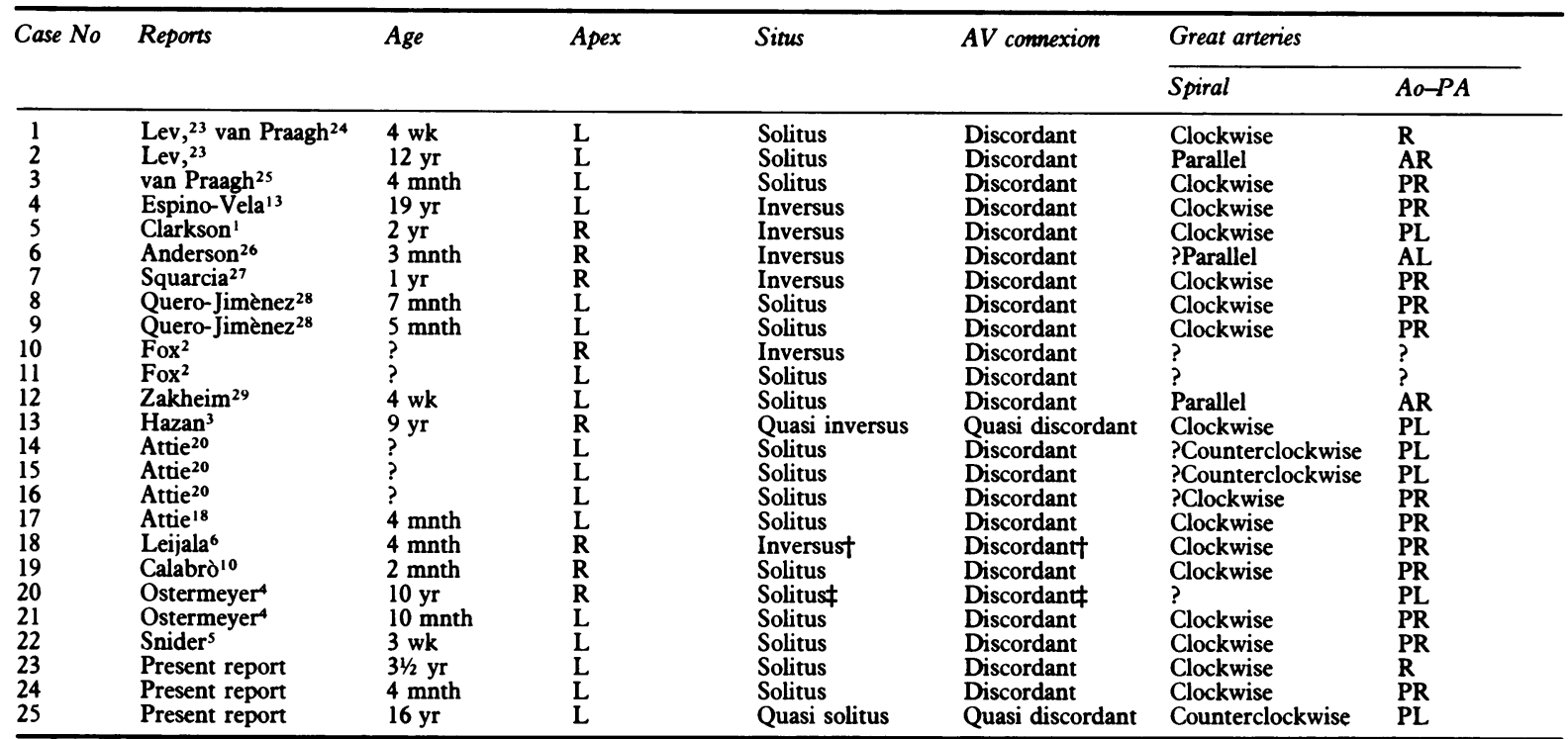

$\mathrm{AL}$, anterior and leftward; AR, anterior and rightward; ASD; atrial septal defect; AV, atrioventricular; AVSD, atrioventricular septal defect; Acc, accessory; CAVO, common atrioventricular orifice; Coarc, coarctation of the aorta; Cont, continuation; IVC, inferior vena cava; L, left; LAVV, left atrioventricular valve; LJAA, left juxtaposition of the atrial appendage; MS, mitral stenosis; MV, mitral valve; PA, pulmonary artery; PAPVC, partial anomalous pulmonary venous drainage; PDA, persistent ductus arteriosus; PL, posterior and leftward; PR, posterior and rightward; PS, pulmonary stenosis; R, right; RA, right atrium; RAA, right aortic arch; RJAA, right juxtaposition of the atrial appendage; RV, right ventricle; SAS, subaortic stenosis; TAHVC, total anomalous hepatic venous connexion; TAPVC, total anomalous pulmonary venous drainage; TV, tricuspid valve; VSD, ventricular septal defect.

*Architectural pattern.

tPossibly quasi inversus and quasi discordant.

$\ddagger$ Possibly quasi solitus and quasi discordant.

there being only 22 reports so far published in the English language (Table). Since both are associated with a single switch in the circulation both may be confused clinically with complete transposition of the great arteries. The irony of our first case is that because total anomalous pulmonary venous return resulted in equalisation of the systemic and pulmonary arterial oxygen saturations, and angiocardiography was suboptimal, neither complete transposition nor isolated atrioventricular discordance ${ }^{10}$ was suspected preoperatively. Careful evaluation of the angiocardiograms with particular attention to the ventricular morphology should have established the correct diagnosis. Though cross sectional echocardiography was undertaken only postoperatively and only in two patients, the features were sufficiently striking to suggest that the diagnosis could have been reached before cardiac catheterisation, as reported by Snider and colleagues. ${ }^{5}$

The Table lists those patients in English language reports with a similar sequential chamber organisation. Three cases previously designated as having "isolated ventricular inversion"11 or "ventricular inversion without transposition ${ }^{12} 13$ have not been included since they definitely or almost certainly had an absent atrioventricular connexion.

The first step in the diagnosis of atrioventricular discordance is to establish atrial situs. ${ }^{14}$ This is not as easy as it seems. In Clarkson's case there was situs solitus of the abdominal viscera and situs inversus of the atria and bronchi. ' In our third case, the bronchial pattern 1516 and atrial appendage morphology as seen at operation indicated left atrial isomerism. This leads us to suspect that the case of Hazan and colleagues ${ }^{3}$ had left isomerism rather than situs inversus. There was an azygos continuation of the inferior vena cava on the left, a common atrium, and a complete atrioventricular septal defect, all commonly associated with left isomerism. ${ }^{9}$ In the lateral angiocardiogram, both pulmonary arteries looped posterior to the trachea, a pattern described by Soto and colleagues as characteristic of left isomerism. ${ }^{17}$ Similar, but not so clear cut, considerations apply to the heart described by Leijala and colleagues ${ }^{6}$ and the first case of Ostermeyer and colleagues. ${ }^{4}$

Thus some diversity exists at the atrioventricular junction in these patients, with even a crisscross relation having been recorded. ${ }^{18}$ There is even more 


\begin{tabular}{|c|c|c|c|c|}
\hline $\begin{array}{l}\text { Ventricular } \\
\text { morphology }\end{array}$ & $\begin{array}{l}\text { Mitral-aortic } \\
\text { continuity }\end{array}$ & Associated defects & Treatment & Result \\
\hline $\begin{array}{l}\text { L } \\
\text { L } \\
\text { L } \\
\text { R } \\
\text { R } \\
\text { R } \\
\text { R } \\
\text { L } \\
\text { L } \\
\text { R } \\
\text { L } \\
\text { L } \\
\text { R } \\
\text { L } \\
\text { L } \\
\text { L } \\
\text { L } \\
\text { R } \\
\text { L } \\
\text { L } \\
\text { L } \\
\text { L } \\
\text { L } \\
\text { L } \\
\text { L }\end{array}$ & $\begin{array}{l}\text { No } \\
? \\
\text { Yes } \\
? \\
\text { Yes } \\
\text { No } \\
? \\
\text { Yes } \\
\text { Yes } \\
? \\
? \\
\text { No } \\
\text { Yes } \\
? \\
? \\
? \\
? \\
? \\
\text { Yes } \\
\text { Yes } \\
\text { Yes } \\
\text { Yes } \\
\text { No } \\
\text { No } \\
\text { Yes }\end{array}$ & $\begin{array}{l}\text { Coarc, VSD, PDA } \\
\text { VSD, PS } \\
\text { VSDs } \\
\text { TAPVC (RA), ASD, VSD, PS, MS } \\
\text { ASD } \\
\text { VSD } \\
\text { VSD } \\
\text { VSD, PDA, hypoplastic TV, supravalvar ring } \\
\text { VSD, RJAA, hypoplastic RV } \\
\text { VSD } \\
\text { VSD, PAPVC } \\
\text { RAA, acc MV tissue, SAS, VSD, PDA } \\
\text { Common atrium; CAVO } \\
\text { ? } \\
\text { ? } \\
\text { ? } \\
\text { Crisscross, LJAA, VSD, RV hypoplasia } \\
\text { Hemiazygos cont on left, TAHVC (RA) } \\
\text { Straddling TV, SAS, VSD, Coarc, PDA } \\
\text { AVSD, partitioned orifices, PAPVC, } \\
\text { TAHVC (right sided atrium) } \\
\text { VSD } \\
\text { VSD } \\
\text { VSD, TAPVC } \\
\text { VSD, PFO } \\
\text { Aneurysm, membranous septum, interrupted } \\
\text { IVC, azygos cont, right aberrant, right } \\
\text { subclavian artery }\end{array}$ & $\begin{array}{l}\text { Medical } \\
\text { Modified baffles } \\
\text { PA banding } \\
\text { L Blalock shunt } \\
\text { Mustard operation } \\
\text { Medical } \\
\text { ? } \\
\text { Blalock-Hanlon shunt, PA banding } \\
\text { Medical } \\
\text { Mustard, VSD closed } \\
\text { Mustard, VSD closed } \\
\text { PDA ligation, atrial septostomy } \\
\text { Mustard operation } \\
\text { ? } \\
\text { ? } \\
\text { Medical } \\
\text { Mustard operation } \\
\text { Medical } \\
\text { Mustard, LAVV repair } \\
\text { Mustard, VSD closed } \\
\text { Senning operation } \\
\text { Repair of TAPVC } \\
\text { Mustard, VSD closed } \\
\text { Mustard operation }\end{array}$ & $\begin{array}{l}\text { Died } \\
\text { Died } \\
\text { Died } \\
\text { Died } \\
\text { Alive } \\
\text { Died } \\
? \\
\text { Died } \\
\text { Died } \\
\text { Alive } \\
\text { Died } \\
\text { Died } \\
\text { Alive } \\
? \\
\text { ? } \\
\text { ? } \\
\text { Died } \\
\text { Alive } \\
\text { Died } \\
\text { Alive } \\
\text { Alive } \\
\text { Alive } \\
\text { Died } \\
\text { Alive } \\
\text { Alive }\end{array}$ \\
\hline
\end{tabular}

diversity at the ventriculoarterial junction, despite the fact that all have ventriculoarterial concordance. Firstly, there is the question of mitral-aortic continuity or discontinuity. This seems of relatively small importance, particularly in the light of the wide range of normality which exists in normal hearts. ${ }^{19}$ Of considerably more importance, particularly to the echocardiographer, is the relation of the great arteries. If the aorta is posterior and the great arteries spiral clockwise, then the parasternal short axis cut or scan will show the "sausage", corresponding to the right ventricular outflow tract and pulmonary trunk, in its normal position to the left of the "circle", the aorta. On the other hand, if (as in Fig. 3) they spiral counterclockwise the picture obtained will be the mirror image of this. Therefore it is vital to ensure that leftright orientation is correct when the echocardiogram is recorded.

As the Table shows, whether or not there is situs solitus or inversus the great arteries almost always in fact spiral clockwise. In fact, our third case is the first reported in which the arteries definitely spiralled counterclockwise, though this was probably the arrangement in two cases described by Attie and colleagues. ${ }^{20}$ Given that clockwise spiralling of the great arteries is the norm, whatever the atrial situs, the frailty of qualifying such terms as ventricular or atrial inversion or non-inversion, ventricular discordance, or atrioventricular discordance with the adjective "isolated"1 1021 becomes immediately obvious. After all, what should be regarded as the normal relation of the great arteries in, for example, situs solitus with atrioventricular discordance and a left hand pattern of ventricular architecture? Is it determined by the atrial situs or the ventricular architecture? If the atrial situs is the determinant, then isolated ventricular inversion implies clockwise spiralling, whereas if ventricular architecture is the determinant, isolated ventricular inversion implies parallel or counterclockwise great arteries. The concept of chirality was emphasised by van Praagh $e t$ al with relation to atrial and ventricular architecture, when they pointed out, for example, that a normal right ventricle (in a D-loop) cannot be superimposed on an inverted right ventricle (in an L-loop), since one is a stereoisomer of the other. ${ }^{22}$ Precisely the same argument applies to spiralling great arteries. Clockwise spiralling great arteries cannot be superimposed on counterclockwise ones. It is therefore difficult to believe that two hearts, both with situs solitus and atrioventricular discordance with a left hand pattern of ventricular architecture, are the result of the same disturbance of morphogenesis if in one heart the great arteries spiral clockwise and in the other counterclockwise. Though physiologically these hearts are identical, anatomically they are quite distinct.

Nevertheless, as far as surgical management of these conditions is concerned, spiralling of the great arteries is unimportant compared with correcting for the atrioventricular discordance or quasi discordance. 
Even if the fact that single unsuccessful surgical case reports are rarely published is borne in mind, it is impressive that all patients save one who are reported to have an interatrial baffle procedure survived. Such a form of repair has the particular advantage that the morphological left ventricle remains supporting the systemic circulation.

FJM is supported by the British Heart and Vandervell Foundations. This work was supported in part by the Child Health Research Appeal Trust.

\section{References}

1 Clarkson PM, Brandt PWT, Barratt-Boyes BG, Neutze JM. "Isolated atrial inversion." Visceral situs solitus, visceroatrial discordance, discordant ventricular d loop without transposition, dextrocardia: diagnosis and surgical correction. Am $\mathcal{F}$ Cardiol 1972; 29: 877-81.

2 Fox LS, Kirklin JW, Pacifico AD, Waldo AL, Bargeron LM Jr. Intracardiac repair of cardiac malformations with atrioventricular discordance. Circulation 1976; 54: 123-7.

3 Hazan E, Baillot F, Rey C, Dupuis C. Isolated ventricular discordance and complete atrioventricular canal in situs inversus. Report of successful surgical repair. $A m \mathcal{F}$ Cardiol 1977; 40: 463-6.

4 Ostermeyer J, Bircks W, Krian A, Sievers G, Hilgenberg F. Isolated atrioventricular discordance. Report of two surgical cases with isolated ventricular inversion. $\mathcal{f}$ Thorac Cardiovasc Surg 1983; 86: 926-9.

5 Snider AR, Enderlein MA, Teitel DF, Hirii M, Heymann MA. Isolated ventricular inversion: twodimensional echocardiographic findings and a review of the literature. Pediatr Cardiol 1984; 5: 27-33.

6 Leijala MA, Lincoln CR, Shinebourne EA, Nellen M. A rare congenital cardiac malformation with situs inversus and discordant atrioventricular and concordant ventriculoarterial connections: diagnosis and surgical treatment. Am Heart $f$ 1981; 101: 355-6.

7 de Leval MR, Bastos P, Stark J, Taylor JFN, Macartney FJ, Anderson RH. Surgical technique to reduce risks of heart block following closure of ventricular septal defect in atrioventricular discordance. $\mathcal{F}$ Thorac Cardiovasc Surg 1979; 78: 515-26.

8 Stark J. Concordant transposition-Mustard operation. In: Stark J, de Leval M, eds. Surgery for congenital heart defects. London, New York: Grune and Stratton, 1983: $331-44$.

9 Macartney FJ, Zuberbuhler JR, Anderson RH. Morphological considerations pertaining to recognition of atrial isomerism. Consequences for sequential chamber localisation. Br Heart f 1980; 44: 657-67.

10 Calabrò, Marino B, Marsico F. A case of isolated atrioventricular discordance. Br Heart f 1982; 47: 400-3.

11 Ando M, Satomi G, Takao A. Atresia of tricuspid or mitral orifice: anatomic spectrum and morphogenetic hypothesis. In: Van Praagh R, Takao A, eds. Etiology and morphogenesis of congenital heart disease. New York: Futura, 1980: 421-87.

12 Dunkman WB, Perloff JK, Roberts WC. Ventricular inversion without transposition of the great arteries. A rarity found in association with atresia of the left-sided (tricuspid) atrioventricular valve. Am F Cardiol 1977; 39: 226-31.

13 Espino-Vela J, De La Cruz MV, Muñoz-Castellanos L, Plaza L, Attie F. Ventricular inversion without transposition of the great vessels in situs inversus. $\mathrm{Br}$ Heart $\mathcal{f}$ 1970; 32: 292-303.

14 Brandt PWT, Calder AL. Cardiac connections: the segmental approach to radiologic diagnosis in congenital heart disease. Curr Probl Diagn Radiol 1977; 7: 1-35.

15 Partridge JB, Scott O, Deverall PB, Macartney FJ. Visualisation and measurement of the main bronchi by tomography as an objective indicator of thoracic situs in congenital heart disease. Circulation 1975; 51: 188-96.

16 Deanfield JE, Leanage R, Stroobant J, Chrispin AR, Taylor JFN, Macartney FJ. Use of high kilovoltage filtered beam radiographs for detection of bronchial situs in infants and young children. Br Heart $\mathcal{F} 1980$; 44: 577-83.

17 Soto B, Pacifico AD, Souza AS Jr, Bargeron LM Jr, Ermocilla R, Tonkin IL. Identification of thoracic isomerism from the plain chest radiograph. $A F R$ 1978; 131: 995-1002.

18 Attie F, Muñoz-Castellanos L, Ovseyevitz J, et al. Crossed atrioventricular connections. Am Heart f 1980; 99: 163-72.

19 Rosenquist GC, Clark EB, Sweeney LJ, McAllister HA. The normal spectrum of mitral and aortic valve discontinuity. Circulation 1976; 54: 298-301.

20 Attie F, Soni J, Ovseyevitz J, Muñoz-Castellanos L, Testelli MR, Buendia A. Angiographic studies of atrioventricular discordance. Circulation 1980; 62: 407-15.

21 Van Praagh R, Weinberg PM, Van Praagh S. Malposition of the heart. In: Moss $\mathrm{AJ}$, Adams $\mathrm{FH}$, Emmanouilides GC, eds. Heart disease in infants, children and adolescents. 2nd ed. Baltimore: Williams and Wilkins, 1977: 394-417.

22 Van Praagh R, David I, Gordon D, Wright GB, Van Praagh S. Ventricular diagnosis and designation. In: Godman MJ, ed. Paediatric cardiology. vol 4. Edinburgh, London, Melbourne, New York: Churchill Livingstone, 1981: 153-68.

23 Lev M, Rowlatt UF. The pathologic anatomy of mixed levocardia. A review of thirteen cases of atrial or ventricular inversion with or without corrected transposition. Am f Cardiol 1961; 8: 216-63.

24 Van Praagh R, Van Praagh S. Anatomically corrected transposition of the great arteries. Br Heart $\mathcal{F} 1967$; 29: 112-9.

25 Van Praagh R, Van Praagh S. Isolated ventricular inversion. A consideration of the morphogenesis, definition and diagnosis of nontransposed and transposed great arteries. Am F Cardiol 1966; 17: 395-406.

26 Anderson RH, Arnold R, Jones RS. D-bulboventricular loop with L-transposition in situs inversus. Circulation 1972; 46: 173-9.

27 Squarcia U, Ritter DG, Kincaid OW. Dextrocardia: angiographic study and classification. Am $\mathcal{F}$ Cardiol 1973; 32: 965-77.

28 Quero-Jimènez M, Raposo-Sonnenfeld I. Isolated ventricular inversion with situs solitus. Br Heart $\mathcal{F}$ 1975; 37: 293-304.

29 Zakheim R, Mattioli L, Vaseenon T, Edwards W. Anatomically corrected malposition of the great arteries (S,L,D). Chest 1976; 69: 101-4. 